\title{
Ética Noir en LA
}

\author{
Mulholland Drive | David Lynch | 2001 \\ Marcos Rafael Cañas Pelayo* \\ Universidad de Córdoba - España
}

Recibido 1 de febrero de 2021; aprobado 23 de abril 2021

\begin{abstract}
Resumen
En su vigésimo aniversario, Mulholland Drive mantiene los enigmas morales que la convierten en un objeto de estudio con múltiples interpretaciones. El largometraje de David Lynch es la lucha entre la fantasía y la realidad, con elementos propios de la ética y el romanticismo. ¿Qué enseñanzas podemos sacar de esta cinta de culto? La combinación de un mundo onírico irreal con la tragedia clásica da como resultado una absorbente experiencia para la audiencia, críticos, estudios filosóficos del cine y cualquier persona fascinada por la experimentación en la narrativa. Se propone una lectura de la película considerando investigaciones previas sobre el misterioso trabajo de Lynch. La historia de Betty/Diane Selwyn, una identidad dual, es una oportunidad para reflexionar sobre la condición humana, sus contradicciones y dilemas. Desde su estreno en 2001 hasta el día de hoy, la audiencia de Mulbolland Drive está destinada a cuestionarse todo lo que creía saber sobre ella.
\end{abstract}

Palabras Clave: cine | ética | fantasía | identidad | moral | romanticismo

Ethics Noir in LA

\begin{abstract}
On the occasion of its twentieth anniversary, Mulholland Drive maintains the moral enigmas that make it the subject of a wide range of interpretations. This David Lynch's movie is the fight between fantasy and reality with elements from ethics and romanticism. What moral lessons can we learn from this cult movie? The blend of an unreal oneiric world and the classical tragedy results in a riveting experience for the audience, the critics, philosophical studies on film and anyone fascinated by narrative experimentation. A reading of the film considering the previous researches on Lynch's mysterious work is proposed. The history of Betty/Diane Selwyn -a dual identity- is an opportunity to reflect on the human condition, its contraditions and its dilemmas. From its premiere in 2001 until nowadays, Mulholland Drive's spectators are led to question everything they thought they knew about it.
\end{abstract}

Keywords: cinema | ethics | fantasy | identity | moral | romanticism

\section{Introducción}

"En principio, Mulbolland Drive iba a ser una serie para televisión. La rodamos como piloto: con un final abierto que diera ganas de seguir viendo más" (Lynch, 2020, p. 95). David Lynch rememora así el material que filmó en 1999 para iniciar una ficción televisiva que se basaría en el suspense alrededor de varios misteriosos eventos en la ciudad de Los Ángeles. No obstante, la cadena $\mathrm{ABC}$ quedó poco convencida del resultado y terminó rechazando el proyecto.

Finalmente, la productora francesa Studio Canal Plus sí se mostró interesada en el piloto, aunque solo adquiriría la obra de Lynch si se reconvertía en una película en lugar de una serie destinada a tener más capítulos. El director aceptó la condición y se modificó el montaje, añadiéndose casi media hora de nuevas escenas que fueron filmadas en aras de lograr el objetivo de cerrar el planteamiento a un único largometraje.

La filmografía de Lynch presenta una heterogénea red de influencias, las cuales han sido analizadas por diferentes especialistas, sobresaliendo algunas clásicas monografías (Chion, 2001), completas revisiones de su trayectoria en lengua castellana (Casas, 2007) y recientes análisis colectivos que han ido desmenuzando su particular universo ficticio (Crisóstomo y Ros, 2017).

La personal forma de concebir el lenguaje cinematográfico por parte de este artista ha exigido distintas estrategias de aproximación por parte de la crítica. En muchos casos, se ha considerado que la mejor forma de

* capemarcos@hotmail.com 
abordarlo es con un notable aperturismo al mundo del subconsciente e ir más allá de la primera impresión a través de la gran pantalla (Nochimson, 2012). Con todo, en pocas ocasiones ha alcanzado un nivel tan desconcertante para dicha faceta como en Mulbolland Drive, elevada hoy a la categoría de película de culto.

Con motivo de los quince años de su estreno, se hicieron varios homenajes, sobresaliendo Retour sur Mulbolland Drive, una reflexión y reinterpretación del film a cargo de otros artistas (Bourriaud, 2017), reflejo de la importancia que siguen manteniendo sus atípicos enigmas.

Desde el punto de vista de la filosofía y la ética, esta cinta ha captado la atención del mundo académico (Devlin y Biderman, 2011), sobresaliendo análisis corales donde se han brindado diferentes lecturas alrededor de esta pieza bajo prismas artísticos, sociales, etc. (Giannopoulou, 2013). Asimismo, el concepto de identidad reviste una gran complejidad que Mulholland Drive muestra en algunas de sus vertientes más interesantes, como veremos a continuación. Trabajos previos catalogan esta obra cinematográfica como "narración polifónica” (Martínez López, 2018), fruto de presentar como protagonista a un sujeto múltiple que habita en dos o más realidades diferentes.

Ambigua de forma intencionada, dentro de los posibles caminos que ofrece el film, optamos en el presente estudio por descifrarla a través de una aproximación a la ética del psicoanálisis (Carrasco, 2020, pp. 28-29) de unos personajes que encierran metáforas del lado luminoso y oscuro del celuloide. Indudablemente, Mulbolland Drive, entre otras calificaciones, bien puede ser catalogada como una metáfora moral.

\section{Declaración de intenciones}

Las escenas iniciales de Lynch siempre son muy significativas. El metraje comienza con un concurso de baile swing con música de jazz, donde las imágenes se superponen, destacando a una joven y sonriente mujer rubia, interpretada por Naomi Watts, acompañada de una pareja de ancianos. De inmediato, esa atmósfera de fiesta queda evaporada por la imagen desaseada de una cama en un apartamento donde alguien duerme bajo las sábanas. Tras un breve fundido en negro aparece el nombre de la calle Mulholland Drive como antesala a una atmosfera amenazante. Es el prolegómeno que Lynch precisa para mostrar una vista aérea de la iluminada ciudad de Los Ángeles en una noche ominosa.

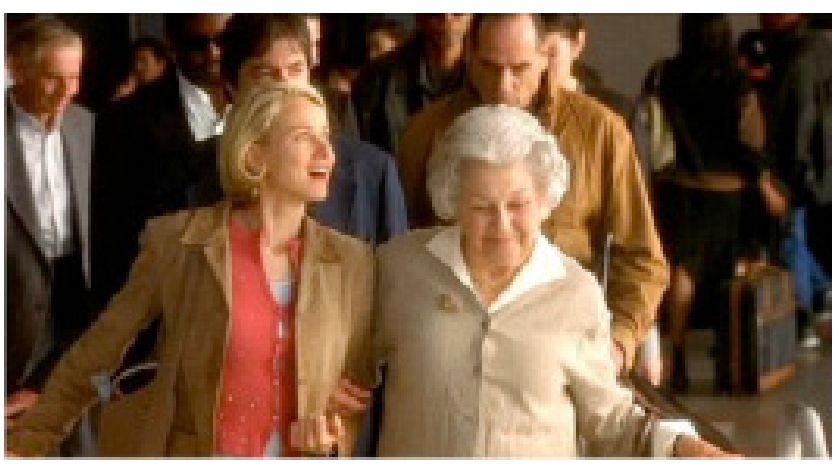

En una limusina, una dama morena, encarnada por la actriz Laura Harring, queda perpleja cuando su conductor y el copiloto se detienen y la amenazan a punta de pistola. Se intuye que quieren hacerla bajar del vehículo para asesinarla en un lugar remoto y sin testigos. Antes de que pueda ocurrir nada, dos vehículos conducidos por jóvenes que compiten en una carrera provocan una colisión con resultados desastrosos. Solamente la mujer consigue sobrevivir; herida y confusa, termina por llegar a una casa lujosa.

El día después, una pareja de detectives estudia el accidente y concluyen que puede haber alguna persona superviviente que haya huido del lugar del siniestro: Mulholland Drive, un enclave que abre el camino a las colinas donde viven varias de las estrellas del celuloide.

Cuando Lynch filmó Carretera perdida (1997), sus títulos de crédito constituyeron una actualización de los exhibidos por el cineasta Otto Preminger en ¿̇́ngel o diablo? (1945), donde la red vial servía como un elemento propio del cine noir más clásico (Corral, 2018, p. 214). Hemos de añadir que tanto en Mulholland Drive como en Carretera perdida el jazz es un elemento más de la trama. Asimismo, el guion de ¿Ángel o diablo?, basada en la novela de Marty Holland, se centra en la contraposición de dos arquetipos de personajes femeninos típicos del cine negro: la femme fatale ante la dama beatifica, sobre las que se debate un forastero que llega por azar a un pueblo desconocido plagado de falsas apariencias. Irónicamente, el film de Preminger vivió otro duelo en el rodaje mantenido por las actrices Alice Faye y Linda Darnell, puesto que el productor Darryl Francis Zanuck terminó favoreciendo la influencia de la segunda al juzgar su rol más atractivo para la audiencia (Figueras, 2013). El choque entre dos actrices buscando lograr un importante papel y sometidas a los caprichosos designios de cargos superiores varoniles es un tema usual en Hollywood, y no parece casual que Lynch tenga como referencia esta pieza de Preminger para construir un relato que se nutrirá de esa diatriba. 
El siguiente marco es en un restaurante llamado Winkie's, donde dos hombres, llamados Dan y Herb conversan. El primero afirma que ha tenido un sueño aterrador acerca de una presencia maligna que vive en el callejón próximo a este local. Ambos salen a investigar y quien tuvo la pesadilla cae presa del pánico al ver una ennegrecida figura cubierta de suciedad que le sonríe

La última presentación del arco inicial es el feliz desembarco en Los Ángeles de Betty Elms, la sonriente chica que se había visto durante el baile de jazz. Se trata de una joven nacida en Deep River (Ontario), quien relata ilusionada a una pareja de la tercera edad que llega a la ciudad con ganas de prosperar como actriz, puesto que su tía Ruth va a permitirle vivir en su lujoso apartamento mientras su adinerada pariente está rodando en Canadá.

Todo parece propicio para Betty cuando se monta en su primer taxi, incluido el letrero Welcome to LA que la recibe, si bien el amable matrimonio que ha viajado con ella luce una sonrisa muy irónica cuando se despiden de ella tras haberle deseado buena fortuna en Hollywood. Bajo las simples apariencias de independientes, las tres tramas tienen profundos vínculos que se enmarcan a la perfección en el universo artístico de David Lynch.

Betty tarda poco en hallar una visita inesperada en su nuevo domicilio, puesto que sorprende en la ducha a la herida mujer que sobrevivió al accidente, la cual está amnésica. Brevemente, la intrusa logra aparentar que es una amiga de Ruth, si bien pronto se desvela la realidad. De entre todos los valores éticos, la verdad es uno de los pilares básicos sobre los que se erige la moral de cada sociedad. Mulholland Drive va presentando siempre personajes que intentan aparentar ser alguien distinto, además de buscar adecuar la ficción creada a su mundo con resultados que se terminan mostrando desastrosos.

$\mathrm{Al}$ preguntar Betty cómo se llama, la intrusa decide coger el nombre Rita, influenciada por un atractivo póster de la película Gilda (1946), el papel que catapultó a la fama a Rita Hayworth (Corral, 2015). En su bolso, hay mucho dinero y una llave azul.

Mulholland Drive es una cinta dedicada a Jennifer Maria Syme, intérprete que había colaborado con Lynch y falleció precisamente en un accidente de tráfico. En cierto sentido, aquí la ficción planteada permite una evasión del dolor de la realidad, puesto que la dama en apuros logra salvar afortunadamente la vida. No olvidemos que antes de iniciarse esa escena, observamos que alguien está soñando. Puede que todo lo que veamos a continuación sea la fantasía onírica de una persona que conoce un hecho terrible y lo está deformando para ha- cerlo agradable. Con Rita, el cineasta plantea el mismo juego que Quentin Tarantino retomaría en Érase una vez en... Hollywood (2019), otro exponente de contraponer la realidad histórica de Los Ángeles frente a una fábula metaficcional donde el cine es la salvación de una víctima inocente: en el caso de Tarantino, la actriz Sharon Tate.

De cualquier modo, hemos de ser cautos a la hora de aceptar esa autorreferencia sin más. El desgraciado accidente de Syme ocurrió cuando Lynch ya tenía escrito el argumento, si bien pudo ser una noticia que le influyese a la hora de acentuar algunos de los planteamientos iniciales. La última vez que fue vista con vida, la joven actriz había estado en una fiesta en casa de Marlyn Mason, quien se había mostrado proclive a participar originalmente en el proyecto de Lynch cuando iba a ser una serie televisiva. La malograda trayectoria de una persona llena de proyectos pudo agudizar la forma tan despiadada en que el cineasta exhibe las colinas de Los Ángeles (Corral, 2018).

En todo momento, la mujer que asume la identidad de Rita es presentada como la metáfora perfecta de la víctima pasiva, arrastrada por acontecimientos que no comprende y privada posteriormente de una supervivencia completa al perder la memoria (Giannopoulou, 2013). Se ve atraída de forma inconsciente por una casa lujosa y que bebe del cine más clásico. Concretamente en un paralelismo nada disimulado con el escritor Joe Gillis, antihéroe en El crepúsculo de los dioses (1950), quien debe refugiarse de sus acreedores en una decadente mansión en las laderas de Sunset Boulevard, donde terminará conociendo a la veterana actriz Norma Desmond, con quien inicia una relación que se revelará fatal para ambos (Staggs, 2003).

El episodio piloto del programa que presuntamente iba a ser Mulholland Drive planteaba pronto una rápida amistad entre Betty y Rita, prometiendo la primera ayudar a la segunda a resolver el misterio alrededor de su fatal accidente. ¿Por qué, entonces, acontece un excursus tan surrealista como la conversación de la pesadilla y posterior descubrimiento en la parte trasera de un local de una misteriosa figura? La premisa ofrece una estructura argumental muy similar al inicio de Twin Peaks, estrenada el 15 de noviembre de 1990. Como su coguionista, Mark Frost, ha confirmado posteriormente (Frost, 2016), Lynch tiene una fascinación por el misterio y la investigación criminal, pero también acompañados de elementos sobrenaturales procedentes de un amplio abanico de influencias: mitología, ritos indígenas, vida inteligente en otros planetas, etc. 
Análisis previos han subrayado que la escena de Winkiés desvirtúa por completo la linealidad argumental (Corral, 2018); incluso podríamos afirmar que sería totalmente prescindible para entender la trama principal. Sin embargo, se inserta justo ahí, tal vez advirtiendo, como el desventurado hombre que se mueve ante el vaivén intencionado de la cámara, que vamos camino de la reconstrucción de una pesadilla cuyo resultado final ya intuimos no va a ser positivo.

\section{El conflicto ético en el arte}

Betty y Rita son las protagonistas de Mulholland Drive, especialmente la primera, como veremos con detalle a continuación. Sin embargo, el metraje dedica también mucha atención a un tercer personaje clave: Adam Kesher, un director de cine cuyo arco argumental parece que va a ser paralelo a la investigación de las dos jóvenes, pero que terminará entrelazándose. Adam, interpretado por Justin Theroux, es entusiasta con su trabajo y toma una postura ética ante las presiones de los hermanos Castigliane, quienes parecen ser el músculo de poderosas fuerzas que quieren presionar al artista para que seleccione en el casting de su nuevo film, titulado Sylvia North Story, a una muchacha llamada Camilla Rhodes.

El posicionamiento de Kesher es perfecto desde el punto de vista moral. Todo parece insinuar que le irá muy bien con la productora y la industria en general si hace ese pequeño favor. No obstante, él coloca como prioritaria su independencia y la justicia de hacer una selección de meritorias ecuánime para todas las candidatas. A través de su película Un tipo serio (2009), los hermanos Coen colocan varios infortunios en un hombre de comportamiento ético intachable, Larry Gopnik, cuyos buenos principios amenazan con derrumbarse ante una serie de catástrofes que le hermanan con el bíblico Job. El propósito de los Coen es forzar al límite a su protagonista para ver si sería capaz de cruzar la línea y cometer un acto que va contra su conciencia.

Sin que Adam Kesher pueda saberlo, será sometido a una tortura semejante. Llega a su casa y sorprende a su esposa teniendo una aventura con el limpiador de la piscina. Furioso, intenta tomarse una pequeña venganza manchando con pintura rosa las joyas de su cónyuge. El resultado final será humillante para el marido, quien es vencido físicamente en una pelea con el amante de su mujer y debe refugiarse en un motel, donde poco después verá confirmado que le han cortado su línea de crédito.
Pese a todo, el cineasta mantiene sus códigos cuando renuncia a una velada proposición sexual que le realiza vía telefónica su secretaria Cynthia.

Irónicamente, su éxodo forzado en el motel le salvaguardará de un peligro mayor. Dos matones son enviados a su domicilio para obligarle a aceptar a Camilla Rhodes como la estrella de su película. Al no encontrar a Kesher, el más corpulento de ellos termina dañando a los dos amantes que no son capaces de contestarle satisfactoriamente sobre el paradero del cineasta. Pese a todo, no es una escena dramática, siendo una violencia irreal, ejercida por un corpulento y parco matón, la clase de sicario del tipo que podríamos encontrar en Los Soprano (19992007), donde su creador David Chase ha declarado su admiración por la obra de Lynch, quien le ha inspirado de forma indiscutible en su planteamiento de los momentos oníricos y ese tipo de violencia estereotipada con efectos tragicómicos (Crisóstomo y Ros, 2017).

Lynch pone incluso parte de su biografía en este retrato hiperbolizado del cineasta que lucha contra las presiones monetarias y las exigencias de quienes están en la cúspide de los grandes estudios. Humillado y todavía con las manchas de pintura, Adam tiene una entrevista en un silencioso y oscuro rancho donde habla con un misterioso individuo que aparece vestido como un rudo vaquero. Lafayette Montgomery, productor cinematográfico en la vida real y amigo personal de David Lynch, da vida a esta especie de fuerza antagónica que hará las veces de Deus Ex Machina: El Cowboy. Se ha subrayado que Lafayette coge las posturas y gestos silenciosos de los primeros pistoleros del cine mudo (Corral, 2018).

$\mathrm{El}$ profesor Alan Nelson encuentra un fuerte vínculo entre El Cowboy y El Castillo, una de las novelas de Franz Kafka (Giannopoulou, 2013). Desentrañando la pieza literaria, Nelson observa una influencia de Kafka en todos los trabajos de Lynch, especialmente en materia de yuxtaponer en escenarios mundanos acontecimientos terribles. No obstante, una de las bases kafkianas, mostrar al sujeto individual sometido ante las estructuras de poder de un modo asfixiante, elevado al máximo en La metamorfosis (Salmerón, 2012), no era tan presente en la filmografía previa de Lynch, quien sí la incorpora por completo en Mulholland Drive. Tal vez incluso exorcizando sus propias reuniones y dificultades para financiar sus ideas ante otros. La pregunta clave es, ¿cuál es el límite que puede tolerar el alma creadora ante la subyugación de la obra artística por fines mercantiles o espurios? (Corral, 2018).

El Cowboy advierte al cineasta de cómo va a ser su relación: "Me verás una vez más si haces las cosas bien, 
y dos si lo haces mal". La insinuación está revestida de la solemnidad que hallamos en una de las leyendas islámicas más célebres: Cita en Samarra. Este relato, muchas veces versionado, analiza lo inevitable del encuentro con la muerte. Igual que el criado huidizo del cuento, Kesher parece una persona manipulada por fuerzas ajenas a su voluntad (Giannopoulou, 2013, pp. 43-44).

De alguna forma, El Cowboy tiene una fuerte alianza con el señor Roque, un enigmático e importante hombre de negocios caracterizado por Joseph Kearney. Pese a tener un aspecto físico poco imponente, una mera llamada suya basta para poner al borde de la ruina a Adam o a cualquier otro cineasta. Siempre delega en otros sus actuaciones, especialmente sicarios mafiosos, además de pronunciar sentencias poco claras que llevan a la ambigüedad. Se ha advertido que sus crípticos mensajes dan una amplia variedad de interpretaciones a las personas que lo escuchan (Giannopoulou, 2013). Es fácil asimilarlo a la forma de proceder del oráculo de Delfos, uno de los centros religiosos más importantes de la Antigüedad Clásica y cuyos sacerdotes se cuidaban de escribir con la suficiente ambivalencia las respuestas o profecías de la Pitia (Scott, 2017).

Tras el arco protagonizado por Adam se produce, junto con la primera escena de Winkie's, uno de los momentos que más rompen la diégesis de Mulholland Drive. Cuando deberían converger las tramas descritas, Lynch rueda con todo detalle la poco hábil ejecución de un sicario llamado Joe de un encargo en una oficina de la parte baja de los Ángeles. El criminal debe hacerse con un libro negro que contiene direcciones. Igual que sucedía con la escena del matón con la pareja de amantes, el posible dramatismo del momento se pierde en la hipérbole y torpeza con que se desarrolla el hecho.

Aunque comienza ejecutando a la persona que custodia el objeto con su pistola silenciada, teniendo opciones de una rápida fuga encubriendo sus pasos con un falso suicidio de la víctima, Joe dispara accidentalmente a la pared, hiriendo a una mujer en la oficina próxima, quien grita desaforadamente. Intentando eliminarla con sigilo, su poca habilidad le lleva a ser detectado por un miembro del personal de limpieza del edificio. Igual que en Trwin Peaks, Lynch aprovecha la ocasión para alargar la escena y ralentizar los sucesos con un efecto tragicómico.

Observando el metraje con detenimiento, vuelve a repetirse la fórmula. El eje más importante de esta parte del film es el dilema moral planteado a un Adam colocado al borde del precipicio, intercalado con una subtrama que parece completamente ajena a su figura bajo las simples apariencias.

\section{Deseos}

Paralelamente a lo descrito, Betty y Rita parecen ir haciendo progresos en sus indagaciones con las técnicas típicas de los relatos pulp, donde un nombre o el encuentro casual lleva al detective de turno a avanzar en la investigación. Ambas mujeres consultan telefónicamente a la policía para informarse del accidente en Mulholland Drive, logrando algunos detalles sobre el siniestro. Realizan la llamada en Winkie's, donde volvemos a tener como secundarios a Dan y Herb. Al observar el nombre de Diane en la identificación de una de las camareras del local, la dañada memoria de Rita la hace sentir conexión con una tal Diane Selwyn. Betty la ayuda a buscar su dirección en la guía de teléfonos de LA.

La amistad entre Betty y Rita va creciendo, hasta el punto que la segunda ayuda en los ensayos a la aspirante a actriz. Lynch realiza un juego muy similar al que podemos apreciar en la comedia ; Qué ruina de función! (1992). En el film de Peter Bogdanovich, asistimos al ensayo y posterior desarrollo de una representación teatral, con los mismos diálogos que, sin embargo, la audiencia disfruta como si fueran nuevos por el contexto diferente en el que suceden. Betty va logrando una gran complicidad con Camilla y, casi de inmediato, Mulholland Drive nos lleva a verla exhibiendo profesionalidad y naturalidad para impresionar al elenco para el que está realizando la prueba (Giannopoulou, 2013, p. 63).

A poca distancia en ese mismo estudio, un desganado Adam termina pronunciando la frase "Está es la chica" cuando, al fin, Camilla Rhodes irrumpe en escena para cantar I've Told Every Little Star, una canción de aspecto inocente, pero que puede esconder lo efímero de la fama. Hipócritamente, es felicitado por algunos de los altos cargos del estudio por lo acertado de una elección que, en realidad, no es suya. Adam renuncia a sus principios por financiar su carrera y obtener calma. Con todo, observa con muchísimo más interés a Betty, con quien tiene un breve cruce de miradas. Recordando su cita con Rita para encontrar a Diane, abandona el plató sin que parezca que el director vaya a poder olvidarla, pese a no conocerla.

A lo largo de su andadura en California, Betty exhibe la fortaleza de una personalidad positiva. Todo le termina saliendo bien. Además, es leal con la cita de su amiga, desoyendo la posibilidad de trabar contacto con un director que podría darle un papel relevante. Junto con Rita, llega al domicilio de la misteriosa Diane Selwyn, solamente para descubrir, tras la mediación de una 
vecina, que se han confundido de apartamento y es otro cercano. Hallan un cuerpo en descomposición, abandonado y en soledad. Es una visión que altera a las dos mujeres, aunque Lynch enseguida introducirá un elemento de sensualidad, siguiendo su propia fórmula en Terciopelo azul (1986), donde la muerte convive perennemente con el erotismo en una mezcla de los horrores vitales con los misterios más placenteros (Delvin y Biderman, 2011).

Pese a que Betty suele tener fortuna en todas las empresas que acomete, quizás ayudar a Rita sea algo que se le va escapando de las manos. En el apartamento de su tía recibe la críptica advertencia de una inquilina de aspecto estrafalario llamada Louise Bonner. Su forma de aconsejarla se parece a las antiguas sibilas, siendo poco clara, si bien la casera, Coco Lenoix (Ann Miller) anima a la actriz a tener muy en cuenta ese pálpito, puesto que Bonner es una especie de clarividente a quien algunas puertas se le abren en ocasiones. Cuando diseñó al agente Dale Cooper para Trwin Peaks, Lynch buscó hacer con él un homenaje a la intuición y los métodos poco ortodoxos de investigar en la ficción, incluyendo el marco onírico (Crisóstomo y Ros, 2017).

Sea como fuere, ninguna de esas señales impide a Betty iniciar una relación sexual con Rita, declarando su amor por ella. Se trata de otro elemento característico de la tragedia clásica, lo inevitable del destino pese a intentar ponerle trabas. Como los troyanos ante las palabras de Casandra, Betty no está dispuesta a perder lo que ha encontrado con Rita, una auténtica pasión. Sin embargo, ¿es sana la relación que quiere Betty o le gusta Rita porque es amnésica, indefensa y vulnerable?

Lynch da una pista clara cuando, poco después, Betty logra convencer a Rita de que se tiña el cabello de rubio. En esos instantes, la dama amnésica parece casi un objeto sin voluntad, una fantasía que Betty puede manejar a su antojo. Transformar a la persona amada para que personifique el propio ideal. Indudablemente, Mulbolland Drive bebe aquí de una de las piezas más célebres de Alfred Hitchcock, Vértigo (De entre los muertos) (1958). En ella, el detective Scottie Fergusson va modificando la apariencia de Judy, la mujer que él quiere convertir en una copia exacta de la belleza idealizada que el policía se ha creado de Madeleine, una víctima asesinada a la que nunca llegó a conocer realmente. Tanto Betty como Scottie convierten el cuerpo de sus pasiones en "la percha que aguanta la hermosa máscara. Bajo el rostro de la máscara subyace el vacío" (Trías, 2016, p. 102). Se trata de una ecléctica mezcla de dos de las pasiones de Lynch y el propio Hitchcock: el gótico y el romanticismo.

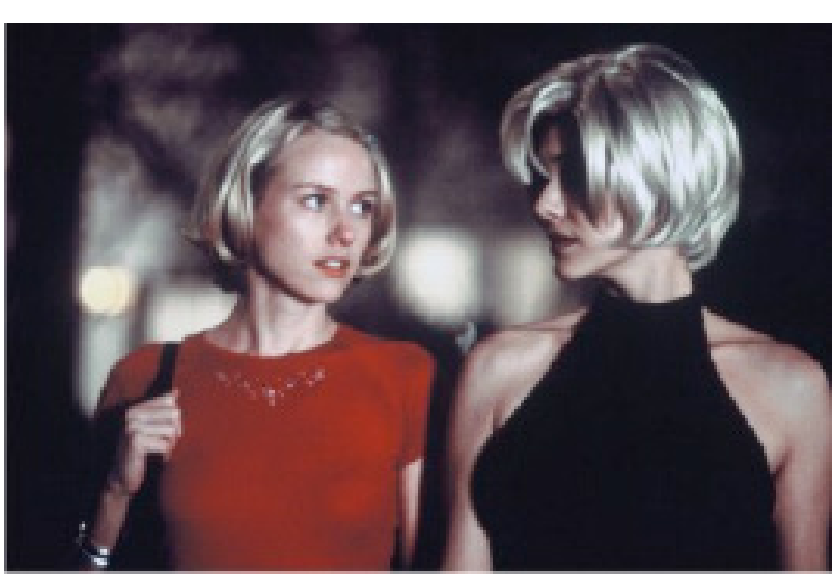

Aunque todo parece haber ido de una forma provechosa para Betty, la consecución de su anhelo, tener una relación íntima con Rita, será justo el momento donde sus sueños escapen a su control.

\section{El silencio de Pandora}

Para el artista es bueno entender el conflicto y la tensión. Son cosas que pueden aportarle ideas. Pero te garantizo que, si soportas demasiada tensión, serás incapaz de crear. Y un exceso de conflicto se interpondrá en el camino de la creatividad. Puedes entender el conflicto, pero no tienes que vivir en él. En las historias, en los mundos que nos adentramos, hay sufrimiento, confusión, oscuridad, tensión e ira. Hay asesinatos; hay toda clase de cosas. Pero el cineasta no tiene que sufrir para mostrar el sufrimiento. Puede enseñarlo, puede mostrar la condición humana, conflictos y contrastes, pero no tiene que pasar por todo ello. Lo orquesta, pero no está dentro. Que sean los personajes los que sufran. (Lynch, 2020, p. 83)

Después de su encuentro íntimo, Rita despertará hablando en lengua castellana, sintiendo la imperiosa necesidad de acudir a un Club llamado Silencio. Es una de esas revelaciones en sueños en las que tanto habría creído también el agente Cooper en Trwin Peaks (Crisóstomo y Ros, 2017). En la madrugada de la populosa ciudad, Betty decide acompañarla a una búsqueda que se entronca con los cuentos infantiles y la mitología grecolatina. De igual forma, la exploración en locales nocturnos para buscar alguna conexión en un caso complicado es uno de los fundamentos de la novela noir y policíaca (Martín Escribá y Canal i Artigas, 2019).

Ambas mujeres acuden a una sala extravagante, casi irreal. Hemos de prestar mucha atención a este escenario porque es una de las incorporaciones al material del que disponía Lynch en el episodio piloto original que iba a ser Mulbolland Drive. Igual que ellas, la audiencia escu- 
cha la desgarradora canción que Rebekah del Rio realiza sobre un amor perdido. Se trata de una pieza plagada de lirismo y, como Rita al despertar del sueño, cantada íntegramente en idioma castellano. El cabaret mostrado por Lynch es una difusa frontera entre la ilusión y lo verdadero, un camino particular donde vida y muerte confluyen (Corral, 2018, pp. 219-220).

La máxima del oráculo de Delfos, "conócete a ti mismo”, orbita sobre este instante de revelaciones. Robert Sinnerbrink, especialista en ensayos que combinan el contenido filósofo con el lenguaje cinematográfico, subraya este momento en el club como el instante donde Betty y Rita no tienen otra posibilidad que afrontar la realidad, paradójicamente en el marco más ilusorio de todos. A diferencia de le enigmática y mística Habitación Roja de Twin Peaks, el Club Silencio está presidido por un fuerte romanticismo derrotado, el mismo que Sinnerbrink detecta en la ya citada Vértigo (Giannopoulou, 2013). Sobre todas las cosas, Mulholland Drive es una deudora de la pasión incluso más allá de la muerte.

El Club Silencio muestra personajes surrealistas como una mujer con su cabello teñido de azul o un inquietante presentador. Ninguna de estas apariciones parece completamente viva o muerta, en un estado de indefinición propio de una especie de limbo. La voz de la cantante sigue resonando a capela pese a desfallecer en el escenario, con Betty y Rita conmovidas, justo cuando la primera halla en su bolso una inquietante caja azul que parece podría abrirse con la llave de Camilla.

Su conexión con los principios de la tragedia clásica vuelve a resonar. Nada menos que con Aristóteles, el preceptor por excelencia a la hora de articularla, quien hablaba de la anagnórisis, el momento donde la ignorancia y ceguera son superadas en aras del conocimiento (Crisóstomo y Ros, 2017). De cualquier modo, esa revelación puede terminar siendo positiva o devastadora. La sabiduría no ayuda a Edipo cuando descubre el acto involuntario que ha cometido, mientras que recuperar la cordura solamente consigue que Hércules caiga en la desolación por las atrocidades fruto de su locura.

Betty y Rita se aproximan a un conocimiento que las hará desaparecer como en un sueño o, tal vez, incluso justo el hecho contrario: el final de una fantasía y el despertar a más prosaica realidad. Ambas mujeres juegan el mismo papel que los dos hombres que conversaban en Winkie's (Nochimson, 2013).

La caja y llave azul nos remiten al mito de Pandora donde están ocultos los horrores del mundo. En el caso del segundo objeto, en este tramo del film se convierte en algo amenazante. No es la primera vez que se utiliza en el cine para abrir y cerrar múltiples opciones de una misma historia. Carolina Martínez López acierta a plantear una comparativa con los pioneros trabajos de Maya Deren (2018), especialmente Meshes of the Afternoon (1943).

Fiel a su propio estilo, Lynch desmitifica su trabajo y contesta: "No tengo ni idea de lo que son" cuando reflexiona sobre qué representan esa caja y llave (Lynch, 2020). Con todo, bien podría ser una simple boutade, máxime en uno de sus pocos trabajos donde admite haber tenido clara la dirección que iba a tomar la historia desde que empezó a pensar en la transformación del piloto en un film independiente.

Aquí podemos plantear otro paralelismo con el cine de Quentin Tarantino; en este caso, con uno de los mcguffins más célebres de este realizador: el controvertido maletín que hallamos en Pulp Fiction (1994) y que tan desesperadamente es buscado por los sicarios de un importante jefe mafioso. No llegamos a descubrir nunca qué contiene (Corral, 2013) aunque es un elemento vertebrador de una historia coral.

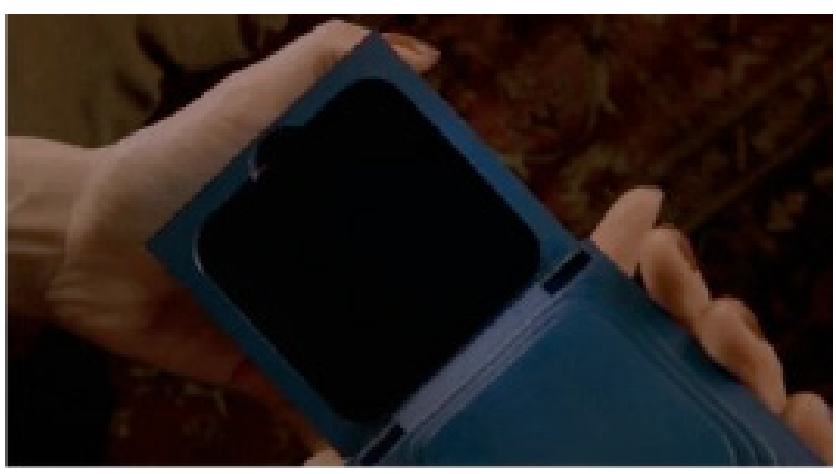

El psicoanálisis ofrece algunas vías de interpretación. La caja azul se asemeja a lo que Sigmund Freud definió como Das Unbeimliche, término que evoca lo siniestro y ominoso en la naturaleza humana, una oscuridad alejada de la luz y donde habitan toda clase de dobles tenebrosos (Martínez López, 2018). Angelo Badalamenti, compositor de Mulholland Drive, subraya que la paradoja de este trabajo es mostrar una oscuridad hermosa.

Betty desaparece cuando Rita introduce la llave. Poco después ella misma dejará de estar y la audiencia quedará presa de un salto espacial donde vislumbramos a la tía Ruth. Mulholland Drive desvanece a sus dos protagonistas para convertirse en algo distinto. El dilema que ha de resolverse es ¿a quién pertenece una obra artística realmente? En una colección de interesantes ensayos sobre la pieza de Lynch, Jean-Michel Durafour considera lícita la interpretación de que la caja desparrama distintas po- 
sibles historias de esa realidad y que terminan cobrando vida propia. Bajo su prisma, podría ser una fábula de la propia afrenta que sufre Adam Kesher: la película que iba a hacer deja de pertenecerle para siempre (Habert y David, 2007).

\section{Juego de espejos}

A partir de la escena en el Club Silencio, Mulholland Drive inicia uno de sus giros más inesperados. Observamos de nuevo la imagen de una persona durmiendo, para descubrir que es la propia Naomi Watts, quien parece escuchar la voz de El Cowboy para despertar en el apartamento de Diane Selwyn, no en la lujosa vivienda de la tía Ruth. De cualquier modo, se reincorporará realmente cuando aparezca una vecina. Se trata de Laura DeRosa (Johanna Stein), la misma mujer que alertó a Betty y Rita sobre su confusión buscando el apartamento correcto.

DeRosa saluda al personaje de Watts llamándola Diane, generando una pronta confusión en la audiencia. Existen miles de posibles reconstrucciones de los acontecimientos presentados. Dentro de los mismos, destacamos y seguimos para nuestro estudio la vertiente que considera a Diane Selwyn como la verdadera identidad de Betty (Hardinghaus, 2018). Si aceptamos esa premisa, Mulholland Drive ofrece una vía interpretativa donde Diane sueña y se proyecta a sí misma ante una gran pantalla (Giannopoulou, 2013). Al convertirse en Betty, siguiendo los postulados de la ética del psicoanálisis, se excluye como sujeto para que aflore toda su esencia y singularidad real. Hay muchos caminos para interpretar Mulholland Drive, todos ellos válidos, siendo esta opción una de las que permiten ir descodificando las pistas de una conciencia atormentada.

Para ello, recurrimos a Jacques Lacan y su teoría de espejo. Según el célebre psiquiatra y psicoanalista francés, los seres humanos obtienen su identidad a través de una imagen distorsionada que construyen en sus primeros años de formación. Diane Selwyn, habida cuenta de la admiración de Lynch por un autor que recuperó muchas de las preceptivas de Sigmund Freud añadiendo matices de otras áreas del conocimiento (Corral, 2018), sería el exponente máximo de ello, puesto que diseña su propio yo a raíz de experiencias de un presunto pasado que está repleto de mentiras sobre las que ella misma se autoconvence.

Sea como fuere, en una reacción lógica a una historia tan abierta a múltiples interpretaciones, hay especialistas en Lynch que renuncian a esa conexión con el psicoanálisis. El mejor exponente de dicha corriente se encuentra en Martha Nochimson, quien cuestiona ese camino, puesto que estima que el paradigma de Lacan concluye que las restricciones humanas imposibilitan abordar la realidad a través de las fantasías creadas por la mente (Nochimson, 2013). Se trata de una afirmación repleta de interés, aunque cabe preguntarse si el director no termina siendo un discípulo de dicha doctrina, pero teniendo un terreno artístico menos restrictivo que el psicoanálisis, pudiendo llevar la teoría a la práctica en los dominios de la ficción, donde su protagonista puede romper todas esas barreras.

En su mundo onírico, había encontrado que DeRosa no mostraba mucha simpatía por Rita. Regresando a la realidad, se confirma que ha sido compañera de piso de Diane durante un tiempo, incluso podría ser posible que tuvieran un affaire, habiendo intercambiado apartamentos. Tras recoger algunas de sus pertenencias, advierte a Diane que dos detectives la están buscando. Los agentes habrían tenido la misma confusión que Betty y Rita en el sueño, lo cual explica que no la localizasen. Una espada de Damocles parece ondear sobre Diane.

La gran pregunta entonces sería quién es realmente esta aparición que supone el verdadero despertar de la película. Se han dado varias estimulantes reconstrucciones de una identidad perdida (Leguil, 2011) de Diane, el reverso tenebroso de todo lo que hemos apreciado en Betty.

$\mathrm{El}$ arte pictórico se convierte también en otra forma de comunicar que el idílico cuento de hadas que supone su Betty dista mucho de ser real. Diane se imagina como ella para protagonizar un fairy tale o cuento de hadas del Hollywood luminoso. Con todo, las pistas en su reconstrucción onírica ya ofrecen costuras. En el apartamento de su idealizada tía Ruth encontramos la pintura Beatrice Cenci, retrato de un notorio personaje de la aristocracia italiana durante el Renacimiento (Hardinghaus, 2018). El morboso juicio que acabó con su ejecución fue uno de los más sonados de su tiempo, salpicado de leyenda y rumorología. Acorde con la tradición, Beatrice había sido la instigadora para que su familia asesinase a su padre (o padrastro en algunas versiones) por los horribles abusos que cometió sobre cada integrante del clan.

Beatrice castiga una falta inmoral de una persona con conducta perniciosa, pero termina siendo castigada ella misma por tomarse la justicia por su mano. De cualquier modo, el problema es más profundo cuando Francesco Cenci había sido absuelto por los tribunales de las denuncias por incesto. En su caso, le exoneraba su estatus 
privilegiado como noble. Existen varias hipótesis de que Diane/Betty habría sufrido abusos por parte de su padre o abuelo (Hardinghaus, 2018) y que el Club Silencio hablaría del comportamiento del resto de su familia (Corral, 2018) ante esa pesadilla.

Unos precedentes así afectarían mucho a una persona que, además, se expone a productores o directores de casting ansiosos de usar su influencia a cambio de favores sexuales. Un mundo de depredadores que convierte en tenebroso el Welcome to LA que había iniciado el periplo idealizado que Diane teje para su alter ego. En algún momento de sus castings, habría conocido a una atractiva mujer que en el sueño ha rebautizado como Rita, homenajeando a una gran estrella del celuloide que sufrió ese mismo drama de abusos juveniles y se cambió el apellido con el que saltó a la fama (Hardinghaus, 2018), siendo asimismo una estrella que sufrió desengaños amargos en sus vínculos con contrapartidas masculinas de la industria (Balmori, 2018). Cambiar de nombre para iniciar un nuevo y dorado futuro.

Naomi Watts muestra una versatilidad que ayuda a la audiencia a distinguir en qué identidad se encuentra. Como Betty, el optimismo lo inunda todo, incluso en las situaciones más tensas. Su Diane es presa de una fuerte angustia en cualquier momento, casi presagiando alguna calamidad por venir. A nivel psicológico, muestra un complejo de inferioridad por su carrera que se acentúa por su amistad/romance con una atractiva meritoria: $\mathrm{Ca}-$ milla Rhodes.

La iluminación explica muchas cosas de la identidad y alma de Diane, algo que vuelve a hermanar el cine de Lynch con Maya Deren (Martínez López, 2018). Por ejemplo, la luz y lámparas rojas en la que podemos observarla en esta parte de la trama acentúa su realidad como una dama de compañía de gente de la industria, varias veces por mediación de la propia Camilla (Hardinghaus, 2018). También se insinúa en su apartamento que ha trabajado en Winkie's como camarera y que su poder económico es bastante más exiguo del de la Betty protegida por su tía Ruth.

Si aceptamos que el sueño de Diane se basa en escenarios que conoce y cambia a su antojo, podemos deducir que ella ha transitado por los callejones donde algunas jóvenes se ven obligadas a ofrecerse, en los cuales el sicario Joe hace indagaciones buscando a la muchacha que obsesiona al señor Roque. Durante un tiempo, su unión con Camilla la hace albergar esperanzas, pero será una relación tóxica a todos los niveles, algo que sigue provocándole alucinaciones donde su amor vuelve.
De hecho, un flashback acentúa el último encuentro sexual entre Diane y su amante, mostrado como algo frustrante y violento en la forma en que ella plantea la relación y el desprecio con el que es recibida. Mulbolland Drive tiene conexiones con Persona (1966), film de Ingmar Bergman, donde las relaciones entre todas las mujeres de la obra terminan siendo una fagocitación, una especie de canibalismo emocional (Corral, 2018).

Existe asimismo un vampirismo en estos vínculos, muy ligados a lo acontecido en otro clásico que penetra en el lado más turbio del espectáculo: Eva al desnudo (1950), pieza que muestra a Eva, una entusiasta y dulce aspirante actriz que logra la protección de la célebre Margo Channing, una gran diva respetada por el círculo de críticos de Broadway. Bajo las simples apariencias, Eva va tratando de absorber todas las facetas de vida de una estrella para desbancarla de forma inmisericorde. Aparte de su indiscutible calidad artística, el trabajo cinematográfico de Joseph Leo Mankiewicz tuvo un accidentado rodaje que algunos especialistas en el Hollywood de los años dorados consideran como la perfecta esencia de los lados más luminosos y oscuros de la industria (Staggs, 2002).

La Camilla Rhodes del mundo real habría sido la vencedora en el casting para The Sylvia North Story. ¿Por qué ese título? Lynch no es un artista que deje los nombres alrededor de sus películas al azar. Se ha propuesto que tenga vínculo con Sylvia (1965), adaptación cinematográfica de la novela de Howard Fast, donde un excéntrico millonario inicia una investigación sobre su prometida, una talentosa poetisa que sufrió abusos paternos en su niñez.

Igual que Beatrice Cenci, Diane tiene un quiebre emocional y unos traumas psicológicos que la harán asumir el papel de jurado y verdugo, desde la fantasía a la realidad.

\section{Una fiesta sin invitación}

Señalamos, como han hecho estudios previos, que uno de los objetivos de Lynch en su filmografía es la descripción de cosas que son invisibles (Casas, 2007, p. 96). $\mathrm{Si}$ bien es reticente a dar excesivas explicaciones sobre sus filmes, parece arrojar claves importantes de Diane cuando afirma que el drama de dicho personaje radica en el deseo, siendo una persona que puede observar la fiesta, pero no está invitada a ella (Rodley, 2005). De hecho, nuestra protagonista se habría beneficiado de haber 
recordado uno de los principios del budismo relativo al dolor que inflige ese anhelo de posesión.

La Diane del mundo real está abusando de forma constante de sustancias estimulantes para sobrellevar el desgaste psicológico que le supone su frustrada carrera. Recibe una llamada de Camilla proponiendo un nuevo encuentro. El teléfono es un elemento fundamental en la identidad dual Betty/Diane.

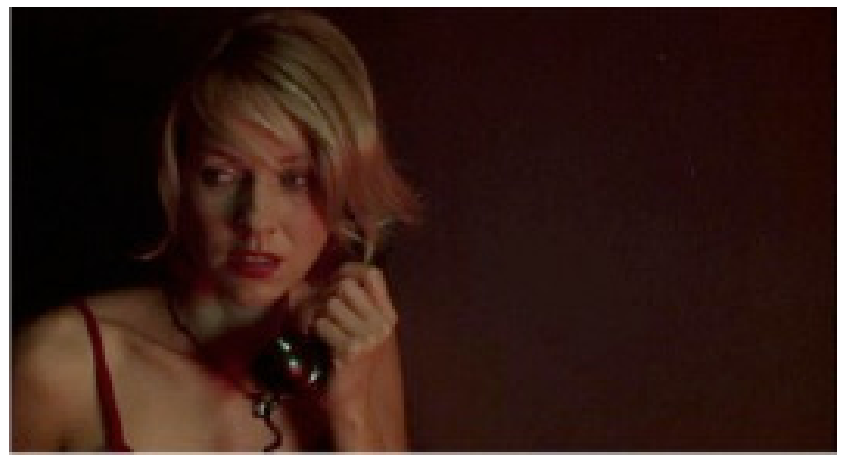

Una simple llamada telefónica puede cambiarlo todo. La imagen de Naomi Watts sosteniéndolo con angustia la conecta con Gloria Grahame, quien dio vida a Laurel Gray en la enigmática En un lugar solitario (1950), film noir que narra el tortuoso romance entre ella y Dixon Steele (Humphrey Bogart), un deprimido guionista en horas bajas que debe adaptar un best-seller sin ningún valor artístico. Laurel Gray usaba con miedo el aparato a la espera en la otra línea telefónica para saber si su temperamental amante es inocente o culpable de un horrible crimen que ha sucedido en Los Ángeles.

Diane ve en esta invitación de Camilla su última oportunidad de reconducirse, recibiendo una limusina que haría las veces del carruaje de Cenicienta. Conforme van subiendo la carrera y colinas de Hollywood, volvemos al punto del inicio del film. El coche se detiene, al igual que en el prólogo. En esta ocasión, no hay ningún intento de asesinato, al abrirse la puerta del coche hallamos a una resplandeciente Camilla que tiende su mano a Diane para marchar con ella por un sendero que parece mágico. Es la última vez que veremos a Diane realmente feliz al sentir ese contacto, imaginando que hay esperanzas de volver a reavivar esa pasión. Es la única escena donde su sonrisa es idéntica a la de Betty.

Lynch rememora aquí uno de los cuentos más afamados: El mago de $\mathrm{Oz}$, una obra con significación política, fantástica y pionera en utilizar a los animales parlantes como objetos transicionales que brindan a los protagonistas humanos las emociones que necesitan (Cashdan, 2019). En Mulholland Drive, el camino de las baldosas amarillas que recorren Diane y Camilla se convierte aquí en el presagio de algo siniestro. No obviemos que nos hallamos ante un trabajo repleto de homenajes a la era dorada del cine estadounidense. La versión más afamada para el celuloide de la pieza literaria de Lyman Frank Baum es tan célebre por su calidad (Álvarez, 2019) como oscura en los entresijos alrededor del rodaje, especialmente para Judy Garland, joven actriz que logró el éxito por su papel, pero sufriendo espionaje y abusos cometidos por miembros del estudio para el que trabajaba. Garland, uno de los iconos de la industria, terminaría falleciendo por una sobredosis de barbitúricos.

Indiscutiblemente, nos hallamos ante el clímax de Mulbolland Drive, la catarsis que va a desencadenar una tragedia que se intuye pendiendo sobre ambas mujeres, remitiendo, como apuntamos previamente, al símil de la espada de Damocles. En el documental The Making of: Mulbolland Drive (Sarde, 2004), buena parte del mismo se centra en cómo se plantearon estos planos donde el lenguaje corporal de Diane y Camilla es fundamental. En el prólogo del largometraje, Lynch insistió mucho en que Laura Harring debía salir del vehículo como si fuese una broken doll, es decir, una muñeca destrozada. Ahora ya no se trata de la desvirtuada e indefensa Rita, es una femme fatale de cuento cuya capa roja incluso evoca a una Caperucita Roja que tendría más que ver con la rupturista versión de Hard Candy (2005) que con la narración original.

De forma pasivo-agresiva, la frustrada ex manda algunos mensajes crípticos sobre la forma en que Camilla logró el estrellato. "Yo nunca fui a Casablanca con Luigi”, es la réplica de la prometida de Adam cuando Diane pronuncia una frase relativa a la conexión de Camilla con un tal Luigi. ¿A qué se refieren?

Película del Hollywood más clásico elevada a la categoría de obra maestra de referencia (Tejero, 2017), Casablanca está llena de momentos que forman parte de la historia del séptimo arte. Asumiendo que, y es lógico en el contexto de dos personas dedicadas al cine, Camilla y Betty están hablando de uno de los personajes del film dirigido por Michael Curtiz: el capitán Louis Renault, uno de los papeles más recordador del afamado actor Claude Rains, apodado Luigi por el protagonista, Rick Blaine (Humphrey Bogart). Se trata de una autoridad francesa forzada a ser colaboracionista con los nazis, aunque es un individuo astuto y cínico que logra moverse con habilidad entre los dos bandos de la II Guerra Mundial sin comprometerse. 
Luigi es un sibarita que aprovecha su condición de autoridad para fines epicúreos y que transgreden la moral constantemente. Toma ventaja de los anhelos de mujeres exiliadas que han huido a Casablanca para conseguir pasajes que las lleven a ellas y sus familias a destinos pacíficos en un mundo sumido por la contienda. A cambio de esos favores sexuales, Renault accede a influir para que logren su objetivo.

El juego entre las dos antiguas amantes es claro a la par que cinéfilo. Diane acusa a Camilla de haber usado sus encantos para lograr importantes papeles, además de emplear a otras colegas como ella en una turbia red. En su fantasía, las fuerzas del señor Roque emplean técnicas mafiosas en una red bizantina de influencias. En la realidad, todo es más prosaico y vulgar.

Adam Keshler confirma aquí la anécdota de cuando descubrió a su mujer con el limpiador de piscinas, pero sin añadir los detalles hiperbólicos que presenciamos. Diane cogió un hecho terrenal y su mundo onírico lo convierte en una especie de tragicomedia con el director cubierto de pintura y despojado de todo. Los sórdidos moteles donde ese Adam imaginado debe recluirse debieron ser los conocidos por ella en LA. Con todo, su cineasta es moralmente positivo, cuando se niega a aceptar el chantaje o a tomar ventaja sobre su secretaria. En la fiesta, el Adam real es más fatuo que artista, placentero en sus decisiones y felizmente cegado de los coqueteos de Camilla con otra joven artista: nada menos que la misma chica que Diane convirtió en Camilla Rhodes para no tener que odiar a su amante en la fantasía. Esa mujer evoca la figura del doppelgänger, una de las que más fascinan a David Lynch. Indudablemente, su cine, como él mismo ha reconocido, tiene una deuda artística con la cineasta Maya Deren, pionera en el cine experimental y en mostrar de una forma próxima al surrealismo el mundo de los sueños en la gran pantalla (Martínez López, 2018: pp. 346-347).

Hay muchos subterfugios en esta fiesta. La única persona empática con Diane, quien es sistemáticamente humillada o ignorada por el resto, es Coco, la madre de Adam. Sin embargo, ¿existe algo detrás de la mano que le tiende consoladora? Es evidente que para la madre del director es verdad el relato que la amiga de Camilla cuenta y que respondería negativamente a la pregunta que el propio Lynch realizaría posteriormente para comprender al personaje de Rhodes: “ ¿Fue solamente el talento lo que ayudó a Camilla?” (Corral, 2018, p. 225).

En su versión onírica, Coco es una casera exigente pero protectora con Betty, a quien urge a tomar decisio- nes importantes con respecto a la inquilina no deseada. Por importante que fuese la herencia de su tía Ruth, Diane Selwyn debería haber gastado una cantidad importante previamente. ¿El subconsciente de Diane en su sueño intenta disimular una oferta de otra naturaleza? ¿Parte de ese dinero provenía de una suegra dispuesta a ayudar a eliminar a una figura sospechosa de caza-fortunas? En caso afirmativo, Coco podría catalogarse dentro del distinguido elenco de la villanía elegante que observamos en Vértigo. El romance gótico protagonizado por Scottie y Judy/Madeleine es tan fuerte que se tiende a olvidar que Gabin Elster, el sofisticado marido de Madeleine, queda completamente impune de sus actos (Trías, 2016).

Al fondo, volverá a aparecer el Cowboy de espaldas. Todo desentona en su figura para la escena más realista de una obra tan surrealista como Mulbolland Drive. Lynch incluso utiliza a otro actor para ese breve instante; tal vez, simplemente el subconsciente de Diane retiene a ese invitado vestido diferente al resto para diseñar su propia trama de poderosas fuerzas que explican su ostracismo en Hollywood. Tanto siendo Betty como Diane, hasta el último instante se niega a considerar que Camilla sea la causa de sus males.

Lynch mima el detalle en una tensa cena de falso glamour, donde todo es mera apariencia para esconder celos y bajos instintos. La taza que sostiene Diane tiene dibujada una sutil alusión a la palabra SOS (Save our ship), fruto de una personalidad desesperada y necesitada de ayuda. Su abuso del café es transmitido por la cámara en la forma que ve borrosos algunos pasajes de la fiesta, siendo la catarsis el anuncio de Adam de su futuro matrimonio con Camilla.

La degradación física es una de las claves que evita que el siguiente y brusco salto temporal resulte confuso para la audiencia. Siguiendo el modelo instaurado por Oscar Wilde en El retrato de Dorian Gray, los actos malignos van cobrando peajes en la apariencia (León, 2011). En el caso de Diane, desaseada y con ojeras, adicta a toda clase de sustancias que la alejen de la realidad, no hay un retrato de ella que la supla en ese castigo del deterioro. Es el momento donde cruza su Rubicón moral particular, entregando la foto de Camilla a un sicario que debe cobrarse la vida de una persona que fue amada por ella. El brazo ejecutor vuelve a ser Joe, aunque aquí se le intuye como un despiadado y eficaz profesional que no errará su misión.

Se hallan en Winkie's, donde Diane ha trabajado como camarera recientemente. A través de una mano indirecta, toma la decisión de tomar venganza. Nomen est 
omen. La máxima latina sellaba el destino de las personas a través de su nombre. Si aceptamos que las identidades reales de nuestras protagonistas son Camilla y Diane, la mitología griega vuelve a ofrecer conexiones que permiten vislumbrar que estamos ante una historia de amor frustrado y culpa. La deidad Camila y la guerrera amazona Diana parecieron tener una visible atracción, sin que ello impidiese a la segunda permitir que la primera cayese a manos del etrusco Arunte (Corral, 2018).

"Esta es la chica" es la frase que aquí adquiere otro sentido. Diane adultera la realidad para convertirla en algo agradable y placentero. En su imaginación, la atractiva rubia que besa a su antigua amante se convierte en la Camilla que consiguió el papel protagonista que ella estaba buscando desesperadamente. Aquí, tiende la foto de su verdadero amor para que Joe identifique a su presa.

Monografías previas prestan una especial atención a la pista número 9, donde Lynch recomendaba que el público viese todo cuanto había alrededor de Winkie's en esa conversación. Diane cruza la línea de la moral para aplicar su venganza, contratando a un sicario de nombre Joe (Hardinghaus, 2018). Allí volvemos a ver a aquel hombre que describirá su pesadilla sobre el monstruo del local al principio de la película. Inquieta por ser descubierta en el crimen que está orquestando, el desconfiado subconsciente de Diane podría rememorar a esa figura del restaurante, bautizándole con un nombre que recuerda al suyo propio: Dan. Es decir, una fusión casi completa de su complejo de culpa y remordimiento. De igual forma, se ha especulado también que la conversación de los dos hombres en Winkie's sería una versión de las sesiones de Diane con su psicoanalista, donde el segundo intentaría que ella dejase de intentar insertar su sueño utópico de Hollywood en la realidad (Devlin y Biderman, 2011).

La llave azul sería el recordatorio de que el crimen se ha cometido. Los avisos de su anterior compañera de piso (y quizás pareja durante un tiempo) sobre las preguntas de los detectives implicarían que la policía va estrechando las indagaciones sobre el asesinato de Camilla. La caja desparramada podría implicar el final de la reconstrucción utópica, los fragmentos del pasado irreal que Diane fabrica para Betty. El libro negro por el que Joe está dispuesto a matar en su sueño podrían ser los datos que la incriminen.

Los ruidos de la puerta llevan a la última alucinación, donde una deformada versión de la pareja de ancianos que conoció en el aeropuerto la asalta de forma monstruosa, llevándola a coger un revólver de su mesilla de noche para suicidarse. Este surrealista desenlace conec- taría con una pieza literaria tan célebre como El corazón delator de Edgar Allan Poe (Iwasaki y Volpi, 2010). Tanto en un caso como en otro asistimos al desmoronamiento del personaje por la culpabilidad.

Existe consenso de crítica y público en considerar que el matrimonio de la tercera edad son los abuelos de Diane, despedidos justo al principio de su fantasía. Previamente, en la dramática cena en casa de Camilla, quizás en uno de los pocos discursos de Mulholland Drive que sean totalmente sinceros, la aspirante a actriz rememora la felicidad y orgullo familiar al lograr el triunfo en el baile que vimos en los créditos iniciales. Un éxito local que se torna en promesa incumplida dentro de Los Ángeles.

No pretendemos establecer esta reconstrucción como la única posible o la más certera de una película plagada de opciones. Existe una amalgama de teorías de sueños dentro de sueños (Hardinghaus, 2018), un concepto muy atractivo que Lynch, uno de los directores más interesados por ese reino onírico, eleva en su filmografía hasta el punto de que cuesta poco ver su legado en ese ámbito para Origen (2010), sobre todo en materia de la arquitectura alrededor de este fenómeno que permite un laberinto que conecta a unos con otros. Son dignas de mención también las teorías relativas a que el trabajo de Lynch podría conectarse con la creencia de la secta pitagórica sobre la transformación de las almas (Martínez López, 2018).

Sin negarlas, una lectura moral ofrece una ruta directa que hace encajar todas las piezas de Mulholland Drive. Para que el recorrido tenga significado en una escena de esa emotividad, debe ser la conciencia de Diane la que intente, en distintas fases de su sueño, rehacer el mal cometido.

De hecho, el productor francés Pierre Edelman logró, para la distribución del film por Europa, que Lynch incumpliese una de sus máximas: permitir al público y a sí mismo un encadenamiento de poderosas secuencias que no estuvieran atadas por las obligaciones argumentales de la narrativa tradicional (Corral, 2018). En esta ocasión, el cineasta tuvo que ofrecer diez pistas a través de preguntas que deberían ayudar a la audiencia a desentrañar el misterio.

\section{Conclusiones}

David Lynch ha catalogado siempre su controversial película como, fundamentalmente, una obra romántica. ¿Qué mayor romanticismo puede darse que intentar mantener intacto, en la medida de lo posible, el mundo 
generado alrededor de un amor no correspondido? Diane cae en la misma tentación que el Borges ficticio que hallamos en la epopeya intimista del cuento El Aleph (2017).

Bajo el punto de vista de la narrativa, Mulholland Drive es una atrevida adulteración del género whodunit, donde el eje central de la trama es descubrir quién realizó un crimen y sus motivaciones. El desafío lanzado sería colocar, al igual que ocurre en Carretera perdida, el misterioso delito relegado a los márgenes del argumento (Delvin y Biderman, 2011).

Por mítica que haya resultado para la historia de la televisión, poseemos fundamentos para plantear que $\mathrm{Mul}$ holland Drive, precisamente por esa azarosa producción que la obligó a tornarse en largometraje, está más próxima al ideal de Lynch que la propia Twin Peaks. Su creador ha reconocido que, de haberse prolongado en el tiempo, el producto habría terminado pasando por manos de otros equipos de guionistas de la cadena $\mathrm{ABC}$, desvirtuando su idea original (Corral, 2018).

No en vano, en ocasiones se ha especulado que las verdaderas causas por las que $\mathrm{ABC}$ no prosiguió con el proyecto de Mulholland Drive podían deberse, en realidad, a la imagen tan poco glamurosa que mostraba de la industria de Hollywood (Hardinghaus, 2018). De hecho, resulta visionaria la forma en que plantea algunos temas de los juegos de poder y abusos sexuales que saltarían a dominio público tras el escándalo del poderoso productor Harvey Weinstein.

Ese dolor y angustia también era contemplado por Naomi Watts a la hora de entender el drama por el que pasan las aspirantes a actrices del film. En una entrevista, terminaría arrepentida de haberse sincerado sobre sus peores momentos cuando era desconocida en Hollywood (Corral, 2018). Titulares sensacionalistas que afirmaban que había contemplado el suicido alejaron el propósito inicial y la idea de Watts durante la promoción de Mulholland Drive: la autoexigencia y el deseo de triunfar en un medio de masas puede hacer perder la perspectiva, llevando a verdaderas depresiones.

La obra de Lynch plantea un lenguaje cinematográfico independiente y que experimenta siempre con novedosos recursos de montaje. De igual forma, ese estilo trascendental no se aleja tanto del modelo literario clásico para narrar. Mulholland Drive es una experiencia sensorial fascinante, pero son precisamente sus códigos ocultos, sugerentes y abiertos, los que la hacen prevalecer en la época de su vigésimo aniversario. El director logra una imaginativa forma de explicar una historia ambivalente y traicionera, si bien es la posibilidad de desentrañar sus pistas lo que proporciona un elemento que logra sobrepasar los límites de un ejercicio audaz y provocador con la cámara.

No en vano, Mulholland Drive es una influencia relevante a la hora de retratar la atmósfera más misteriosa de Los Ángeles, basta pensar lo poco que costaría ubicar a sus personajes en la reciente Lo que esconde Silver Lake (2018), donde David Robert Mitchell retoma el tono surrealista de Lynch para añadir su propia visión de las teorías de la conspiración y misterios que esconden los grandes hitos de la cultura pop.

\section{Referencias}

Álvarez, J. L. (Ed.) (2019). El mago de Oz: El libro del 80 aniversario. Notorious Ediciones.

Balmori, G. (Ed.) (2018). El universo de Rita Hayworth. Notorious Ediciones.

Borges, J. L. (2017). El Aleph. Debolsillo.

Bourriaud, N. (Ed.) (2017). Retour sur Mulholland Drive. La Panacée y Silvana Editoriale.

Carrasco, J. (2020). "Dallas Buyers Club” o cómo resistirse a la deriva segregativa. Ética E Cine, 10 (3), 27-33. https://doi. org/10.31056/2250.5415.v10.n3.30883

Casas, Q. (2007). David Lynch. Cátedra.

Cashdan, S. (2019). La bruja debe morir: De qué modo los cuentos de hadas influyen en los niños. Debate.

Chion, M. (2001). David Lynch. Cahiers du cinéma.

Chion, M. (2003). David Lynch. Paidós.

Corral, J. (2013). Quentin Tarantino: Glorioso bastardo. Dolmen.

Corral, J. M. (2018). David Lynch: Cruzando la cortina roja. Dolmen.

Crisóstomo, R. y Ros, E. (2017). Regreso a Twin Peaks. Errata Naturae.

Deverly, F. (19 de diciembre 2011). Un café en Mulholland Drive [Publicación de Blog]. Recuperado de https://cinebug.wordpress. com/2011/12/19/un-cafe-en-mulholland-drive/ 
Devlin, W. J. y Biderman, S. (2011). The Philosophy of David Lynch. The University Press of Kentucky.

Figueras, M. (17 de febrero de 2013). Film noir: ‘¿Ángel o diablo?’ de Otto Preminger [Publicación de Blog]. Recuperado de https:// www.espinof.com/cine-clasico/film-noir-angel-o-diablo-de-otto-preminger

Frost, M. (2016). Trin Peaks: Una novela. Planeta.

Giannopoulou, Z. (Ed.). (2013). Mulholland Drive (Philosophers on Film). Routledge.

Habert, C. y David, N. (Eds.). (2007). Mulholland Drive. De La Transparence.

Hardinghaus, C. (2018). The Key to Mulholland Drive: Understanding David Lynch and his Street of Darkness. Amazon Italia Logistica.

Iwasaki, F. y Volpi, J. (Eds.). (2010). Edgar Allan Poe: Cuentos completos. Páginas de Espuma.

Leguil, C. (2011). Locura y femineidad. Con Diane Selwyn en Hollywood. Virtualia: Revista digital de la EOL (22). http://www. revistavirtualia.com/articulos/320/lo-que-la-sublimacion-ensena/locura-y-femineidad-con-diane-selwyn-en-hollywood

León, V. (Ed.) (2011). El Retrato de Dorian Gray [Edición sin censura]. Reino de Cordelia.

Lynch, D. y McKenna, K. (2018). Espacio para soñar. Reservoir Books.

Lynch, D. (2020). Atrapa el pez dorado: Meditación, conciencia y creatividad. Reservoir Books.

Martín Escribá, À. y Canal i Artigas, J. (2019). A quemarropa: La época clásica de la novela negra y policíaca. Alrevés Editorial.

Martínez López, C. (2018). La multiplicación de la identidad en Mulholland Drive de David Lynch y en la “Trilogía de la autorrepresentación” de Maya Deren. Imagofagia: Revista de la Asociación Argentina de Estudios de Cine y Audiovisual (18), $344-365$.

Nochimson, M. P. (2012). The Passion of David Lynch. University of Texas Press.

Nochimson, M. P. (2013). David Lynch Swerves: Uncertainly from Lost Highway to Inland Empire. University of Texas Press.

Rodley, C. (2005). Lynch on Lynch. Faber \& Faber.

Salmerón, M. (Ed.). (2012). Franz Kafka: La metamorfosis. Austral.

Sarde, A. (Productor) y Dessites, D. (Director). (2004). The Making of: Mulholland Drive [Documental]. Studio Canal Collection.

Scott, M. (2017). Delfos: Historia del centro del mundo antiguo. Ariel.

Staggs, S. (2002). Desnudando a Eva. T \& B Editores.

Staggs, S. (2003). El crepúsculo de los dioses: Billy Wilder, Norma Desmond y el sueño oscuro de Hollywood. T \& B Editores.

Tejero, J. (2017). Casablanca. Bookland Press.

Trías, E. (2016). Vértigo y pasión: Un ensayo sobre la película Vértigo de Alfred Hitchcock. Galaxia Gutenberg. 